\title{
Remineralizing effect of commercial fluoride varnishes on artificial enamel lesions
}

\author{
Fernanda Alvarez de GODOI ${ }^{(a)}$ \\ Natália Russo CARLOS(a) iD \\ Enrico Coser BRIDI(a) \\ Flávia Lucisano Botelho do AMARAL(a) \\ Fabiana Mantovani Gomes \\ FRANÇA(a) $^{(i)}$ \\ Cecilia Pedroso TURSSI(a) \\ Kamila Rosamilia KANTOVITZ(a) ID \\ Roberta Tarkany BASTING(a) iD \\ (a) São Leopoldo Mandic Research Institute, \\ Campinas, SP, Brazil.
}

Declaration of Interests: The authors certify that they have no commercial or associative interest that represents a conflict of interest in connection with the manuscript.

Corresponding Author:

Roberta Tarkany Basting

E-mail: rbasting@yahoo.com

hitps://doi.org/10.1590/1807-3107bor-2019.vol33.0044

Submitted: August 9, 2018

Accepted for publication: April 8, 2019

Last revision: April 26, 2019
Abstract: The aim of this study was to evaluate soluble and insoluble fluoride concentrations in commercial varnishes, and their remineralization effect on artificial caries enamel lesions using surface and cross-sectional microhardness evaluations. Forty bovine enamel blocks were separated into four groups $(n=10)$ : control (no treatment), Enamelast (Ultradent Products), Duraphat (Colgate-Palmolive) and Clinpro White Varnish (3M ESPE). Surface enamel microhardness evaluations were obtained, artificial enamel caries lesions were developed by dynamic $\mathrm{pH}$-cycling, and the varnishes were then applied every 6 days, after which the enamel blocks were submitted to dynamic remineralization by $\mathrm{pH}$ cycles. After removal of the varnishes, the enamel surfaces were reassessed for microhardness. The blocks were sectioned longitudinally, and cross-sectional microhardness measurements were performed at different surface depths (up to $300 \mu \mathrm{m}$ depth). Polarized light microscopy images (PLMI) were made to analyze subsurface caries lesions. The fluoride concentration in whole (soluble and insoluble fluoride) and centrifuged (soluble fluoride) varnishes was determined using an extraction method with acetone. The data were analyzed to evaluate the surface microhardness, making adjustments for generalized linear models. There was a significant decrease in enamel surface microhardness after performing all the treatments $(p<0.0001)$. Enamelast and Duraphat showed significantly higher enamel microhardness values than the control and the Clinpro groups $(p=0.0002)$. Microhardness loss percentage was significantly lower for Enamelast ( $p=0.071$; One-way ANOVA). PLMI showed that subsurface caries lesions were not remineralized with the varnish treatments. No significant differences in the in-depth microhardness levels ( $p=0.7536$; ANOVA) were observed among the treatments. Enamelast presented higher soluble and insoluble fluoride concentrations than the other varnishes $(p<0.0001$; Kruskal-Wallis and Dunn tests). Enamelast and Duraphat varnishes promoted enamel surface remineralization, but no varnish remineralized the subsurface lesion body. Although insoluble and soluble fluoride concentration values did not correspond to those declared by the manufacturer, Enamelast presented higher fluoride concentration than the others.

Keywords: Dental Enamel; Fluorides; Paint; Tooth Remineralization. 


\section{Introduction}

The process of enamel demineralization is caused by several bacteria-metabolized acids, and can be reversed to make the lesion inactive. One of the most well-known and important measures for dental caries control and treatment is mechanical biofilm control, which must be associated with an appropriate level of fluoride exposure. ${ }^{1,2}$

Fluoride solutions come in low concentration for daily use, such as toothpastes and mouthwashes, and higher concentrations for professional application, such as fluoride gels and fluoride varnishes. ${ }^{3}$ The advantages of varnishes are their simple application and prolonged contact with the demineralized surface of the enamel. ${ }^{4,5}$ They are also an important adjuvant in the control and treatment of white spot caries lesions. ${ }^{6}$ Gao et al. ${ }^{7}$ showed that the use of a 5\% sodium fluoride varnish can remineralize incipient caries lesions, thus making this option an important method to inhibit enamel demineralization. ${ }^{8}$

Thickening agents such as colophony resin, gums and waxes have been added to varnishes to promote and prolong their contact time with the tooth surface. A longer contact time boosts the reactivity of the fluoride in the varnish with the enamel, to promote the formation of greater calcium fluoride $\left(\mathrm{CaF}_{2}\right)$ reservoirs weakly bound to the substrate, ${ }^{9}$ on which the enamel demineralization effect is concentration-dependent. ${ }^{10}$ However, the sodium fluoride $(\mathrm{NaF})$ released by the varnish may constitute only a weak release, since hydrophobic colophony resin is solubilized only in ethanol. ${ }^{11}$

Thus, it is recommended that the varnish be kept on the enamel for a longer period to enable greater formation of $\mathrm{CaF}_{2}$ reservoirs on the enamel. ${ }^{12,13}$ Although there is no consensus on the recommended varnish retention time on the enamel-which has been reported to range between 4 hours ${ }^{12,14}$ and the next day ${ }^{15,16,17,18}$ - manufacturers have modified the formulation to prolong the contact time of these agents on the dental enamel, and have developed patented components that promote greater contact, such as Enamelast varnish (Ultradent Products, South Jordan, USA). Other varnish components include tricalcium phosphate, which can activate enamel remineralization (Clinpro White Varnish, 3M ESPE, Saint Paul, USA), thus releasing calcium and phosphate ions into the saliva. This release not only promotes the deposition of minerals on the surface of the enamel, but also potentiates remineralization of the subsurface lesion body. ${ }^{19,20}$

Some studies investigated whether these varnishes: 1) release enough fluoride in the surrounding storage media to allow the formation of $\mathrm{CaF}_{2}$ reservoirs on the enamel substrate and/or, 2) present a remineralization effect on artificial enamel lesions. . $11,21,22,23,24,25$ Only Fernández et al. ${ }^{11}$ evaluated the fraction of fluoride soluble in varnish needed for immediate reaction with hard dental tissues to form $\mathrm{CaF}_{2}$-like products, and the insoluble fluoride particles present in the varnish matrix, which could prolong the reaction when dissolved by saliva.

Thus, the aim of the present study was to investigate the in vitro remineralization effect of fluoride varnishes on artificial enamel caries lesions, and the soluble and insoluble fluoride concentrations of the varnishes. The null hypotheses tested were that: a) there were no differences in the remineralization effect of the different fluoride varnishes evaluated, and b) there were no differences in the fluoride concentrations of different varnishes, whether whole (containing soluble and insoluble fluoride) or centrifuged (containing only soluble fluoride).

\section{Methodology}

\section{Ethical aspects and enamel block preparation of the artificial caries lesions}

The experiment was submitted to and approved by the Animal Ethics Committee (number 2016/025). Forty enamel blocks from bovine incisors were obtained from the flatter regions of the vestibular surface. The teeth were sectioned using a double-sided diamond disc (KG Sorensen Indústria e Comércio, Barueri, $\mathrm{SP}$, Brazil) mounted on a handpiece, yielding dental blocks $4 \mathrm{~mm}$ wide $\times 4 \mathrm{~mm}$ long $\times 4 \mathrm{~mm}$ thick.

A 2-mm-thick layer of wax was applied to the entire block, except the buccal face. The enamel blocks were embedded individually in polyester resin. The enamel blocks were ground flat with a rotary electric polisher (Ecomet 250, Buehler, Lake Bluff, 
USA) coupled to a rotary head (Buehler Automet 250, Buehler, Lake Bluff, USA) and aluminum oxide abrasive paper (Arotec S/A Ind. e Com., Cotia, Brazil) of two different granulations: 600 and 1200, and then polished with $0.3 \mu \mathrm{m}$ aluminum paste (Alfa Micropolish, Buehler, Lake Bluff, USA) and felt cloth. The blocks were cleaned ultrasonically in deionized water for 10 minutes to remove any residue from the polishing procedure.

Microhardness measurements were performed to select the enamel blocks that had similar baseline microhardness values. The blocks were assigned to one of the four treatment groups (Table 1). A statistical test (ANOVA) was used to evaluate whether the mean microhardness values among the four treatment groups were similar, with a $p$ value of 0.9996 . The size effect for this initial selection was low $(\mathrm{f}=0.0177)$, which indicated that the use of $n=10$ would reach a power of 0.96 for the comparisons between groups, and a power of 0.99 for the comparisons between initial and final timepoints.

\section{Artificial enamel caries lesions induction}

The model for inducing artificial caries lesion used the following protocol by Manarelli et al. ${ }^{26}$ The dental blocks were immersed individually into plastic bottles containing $32 \mathrm{~mL}$ of solution with $1.3 \mathrm{mmol} / \mathrm{L}$ of calcium nitrate tetrahydrate and $0.78 \mathrm{mmol} / \mathrm{L}$ of sodium dihydrogen phosphate monohydrate in $0.05 \mathrm{~mol} / \mathrm{L}$ acetate buffer, $\mathrm{pH}=5.0,0.03 \mathrm{ppm}$ fluoride for $16 \mathrm{~h}$ at $37^{\circ} \mathrm{C} .{ }^{5,27}$

\section{Varnish application and remineralization cycles}

The enamel was then treated according to the respective group. In the CON (control) group, no varnish was applied. In the ENA (Enamelast) and DUR (Duraphat) groups, a thin layer of varnish was applied using a microbrush. In the CLI (Clinpro White Varnish) group, the material was manipulated after dispensing equal parts of the liquid and the paste components using a spatula. Then, a thin layer was applied using a microbrush.

The blocks were submitted to 6 days of $\mathrm{pH}$ cycling for induction of remineralization, as described by Vieira et al. ${ }^{28}$ First the varnish was applied and then the blocks were immersed in a remineralizing solution $(1.5 \mathrm{mmol} / \mathrm{L}$ calcium, $0.9 \mathrm{mmol} / \mathrm{L}$ phosphate, $150 \mathrm{mmol} / \mathrm{L}$ potassium chloride in $0.1 \mathrm{~mol} / \mathrm{L}$ cacodylate buffer, $\mathrm{pH}=7.0,0.05 \mathrm{mgF} / \mathrm{mL}, 1.1 \mathrm{~mL} / \mathrm{mm}^{2}$ ) for 4 hours, and subsequently submitted to demineralization (2.0 mmol/L calcium and phosphate in $75 \mathrm{mmol} / \mathrm{L}$ acetate buffer, $\mathrm{pH}=4.7,0.04 \mu \mathrm{gF} / \mathrm{mL}, 2.2 \mathrm{~mL} / \mathrm{mm}^{2}$ ) for 2 hours. ${ }^{26}$ The varnishes were removed with a scalpel blade and acetone, ${ }^{12}$ after which the blocks were transferred to a new remineralizing solution for 18 hours. A new layer of varnish was reapplied at the beginning of each cycle.

\section{Microhardness evaluations}

The enamel microhardness analyses were performed with a digital microhardness tester (Pantec HVS 1000, Panambra, São Paulo, Brazil) and a Knoop-type indenter with a static load of 25

Table 1. Treatment groups, varnish composition and manufacturers

\begin{tabular}{|c|c|c|}
\hline Varnish/ Group/ Lot number & Composition (\% of weight)/ ppm F & Manufacturer (state, city, country) \\
\hline Enamelast/ ENA/ D030Y & $\begin{array}{l}\text { Synthetic resin }(<50) \text {, ethyl alcohol }(<15) \text {, sodium } \\
\text { fluoride }(<5) \text {, methyl ester of hydrogenated rosin } \\
(<5) \text {, citric acid }(<3) / 22,600 \text { ppm } \mathrm{F}\end{array}$ & $\begin{array}{l}\text { Ultradent Products (South Jordan, Utah, } \\
\text { USA) }\end{array}$ \\
\hline Duraphat/ DUR/ $11.14-3$ & $\begin{array}{l}\text { Colophony }(10-<40) \text {, ethanol }(10-<30) \text {, saccharin } \\
\begin{array}{c}(<1) \text {, isoamyl acetate }(<1) \text {, sodium fluoride } \\
(<5) / 22,600 \text { ppm } \mathrm{F}\end{array}\end{array}$ & $\begin{array}{c}\text { Colgate-Palmolive (GmbH, Waltrop, } \\
\text { Germany) }\end{array}$ \\
\hline Clinpro White Varnish/CLI/ N171993 & $\begin{array}{l}\text { Pentaerythritol glycerol ester of colophony resin } \\
(30-75) \text {, n-hexane }(10-15) \text {, ethyl alcohol }(1-15) \text {, } \\
\text { sodium fluoride }(1-5) \text {, flavor enhancer }(1-5) \text {, } \\
\text { thickener }(1-5) \text {, flood grade flavor }(1-5) \text {, modified } \\
\text { tricalcium phosphate }(<5) / 22,600 \mathrm{ppm} \mathrm{F}\end{array}$ & 3M ESPE (Saint Paul, MN, USA) \\
\hline
\end{tabular}


$\mathrm{g}$ for 5 seconds. Five microhardness measurements were made at baseline (SH - before induction of subsurface caries lesion) and after the treatments (SH1 - after remineralization induction cycling), performed at the center of the enamel surface, and measuring $100 \mu \mathrm{m}$ between indentations. The percentage of surface microhardness loss (\% SH) was calculated according to the following formula: $\% \mathrm{SH}=[(\mathrm{SH} 1-\mathrm{SH}) /(\mathrm{SH} \times 100)]$.

The in-depth microhardness was evaluated by sectioning the enamel block longitudinally in the center of the block. Only one section of the cut fragments was embedded in polyester resin (Massa Fix, Royal Polímeros Indústria e Comércio de Produtos Químicos, Osasco, Brazil). The other section was stored for caries lesion analysis by polarized light microscopy.

The surfaces subjected to the microhardness tests were polished with abrasive papers impregnated with aluminum oxide and having 600 and 1200 granulation (3M do Brasil, Sumaré, Brazil), in a pneumatic rotary electric polishing machine (Ecomet 250, Buehler Ltd, Lake Bluff, USA), water cooled at a rotational speed of $600 \mathrm{rpm}$ for 1 minute at $50 \mathrm{~N}$ load. The abrasive papers were changed after every five specimens. Polishing was performed using a $0.3 \mu \mathrm{m}$ alumina suspension (Alfa Micropolish, Buehler, Lake Bluff, USA) with a felt cloth. The blocks were cleaned ultrasonically in deionized water for $10 \mathrm{~min}$ to remove any residue from the polishing procedure.

A sequence of 14 indentations at different surface depths $(10,20,30,40,50,60,80,100,120,140,160,180$, 200 and $300 \mu \mathrm{m})^{26}$ was performed in the center of the block to obtain the hardness values (KHN).

\section{Polarized light microscopy analysis}

The analyses under polarized light microscopy were performed by washing the stored dental sections for 24 hours in several exchanges of distilled and deionized water. The sections were then polished using abrasive papers of 120,400 and 600 granulation, to obtain lamellae approximately $100-\mu \mathrm{m}$ thick, kept in distilled and deionized water until microscopic analysis. The thickness of the enamel lamellae was measured with a digital caliper (Mitutoyo, Itu, Brazil). The preparation of the dental hemi-sections was performed on the opposite face of the section used for the cross-section microhardness test. The preparation method enabled 3 to 4 specimens to be obtained from each group for polarized light microscopy analysis.

Qualitative analyses of the microstructural changes produced in the enamel after induction of the artificial caries lesion were performed according to Silverstone. ${ }^{29}$ The enamel lamellae were studied under a microscope (Nikon Eclipse Ci-S Microscope, Nikon Corporation, Chiyoda-ku, Tokyo, Japan), with a polarizing filter and analyzer, using water as the imbibition medium. This procedure enabled observation of the surface lesion and the lesion body in its extent, according to the treatment types used. The images were photographed at 40X magnification for qualitative analysis of lesion extension. The evaluations were performed without the examiner knowing what group each sample belonged to, therefore constituting a blind study.

\section{Determination of fluoride concentration in varnish}

The fluoride concentration in the whole (soluble and insoluble fluoride) and centrifuged (soluble fluoride) varnishes was determined using a standardized extraction method with acetone. ${ }^{11}$ Previously, preliminary tests were performed to achieve a better method of solubilizing the varnishes to provide the fluoride concentration. The centrifugation procedure consisted of placing the varnish in an Eppendorf tube and centrifuging for 5 minutes, with a centrifugal acceleration of $11,000 \mathrm{~g}$ to collect the supernatant of the varnishes. Afterwards, the varnishes were weighed $(10 \pm 0.1 \mathrm{mg})$ in a centrifuge microtube to which $100 \mu \mathrm{L}$ of acetone was added. After vigorous homogenization in a vortex for $15 \mathrm{~s}$ to ensure complete varnish dissolution, the extracts of whole or centrifuged varnishes were transferred to 100 - or 10-mL volumetric flasks, respectively, and the microtube was washed three times with $1 \mathrm{~mL}$ of water, and three times with up to $100 \mu \mathrm{L}$ of acetone for total varnish removal. The extract was diluted to 100 or $10 \mathrm{~mL}$ using purified water, for whole or centrifuged varnish, respectively. The fluoride concentration was buffered with TISAB II. After obtaining a standard fluoride analysis curve of 0.9948 , the varnish solutions were measured using a specific ion electrode. 


\section{Statistical analysis}

The exploratory analysis of the surface microhardness indicated that the data did not meet the assumptions of the analysis of variance. A linear model was used to calculate the linear regression model for microhardness, and one-way ANOVA to determine the percentage of loss.

Cross-section enamel microhardness (in-depth) was determined after performing the exploratory analysis of the data, by applying analysis of variance in subdivided plot schemes, where the plots were represented by the treatments and the subplots, by the timepoints and distances. Multiple comparisons were performed using the Tukey test.

Regarding the fluoride concentration measurement, the data did not meet the assumptions of parametric analysis applying the Kruskal-Wallis and the Dunn multiple comparison tests. All the analyses were

Table 2. Enamel surface microhardness $\left(\mathrm{kgf} / \mathrm{mm}^{2}\right)$ mean (standard deviation) according to the treatment applied, and the before and after treatment values.

\begin{tabular}{lcc}
\hline Treatment & \multicolumn{1}{c}{ Initial } & After treatment \\
\hline Control & $465.12(35.20) \mathrm{Aa}$ & $104.82(40.80) \mathrm{Bb}$ \\
Enamelast & $466.38(37.24) \mathrm{Aa}$ & $215.92(145.17) \mathrm{Ba}$ \\
$\begin{array}{l}\text { Duraphat } \\
\begin{array}{l}\text { Clinpro White } \\
\text { Varnish }\end{array}\end{array}$ & $466.46(34.65) \mathrm{Aa}$ & $198.16(33.32) \mathrm{Ba}$ \\
\hline
\end{tabular}

Means followed by different letters (uppercase in rows and lowercase in columns) are different. performed using SAS software (SAS Institute, Cary, NC, USA, Release 9.2, 2010) and R (R Core Team, 2015. R: A language and environment for statistical computing, R Foundation for Statistical Computing, Vienna, Austria. URL https://www.R-project.org/), with a significance level of $5 \%$.

\section{Results}

There was significant interaction between the treatments applied and the before and after treatment for surface microhardness $(p=0.0002)$. The microhardness values decreased significantly following the $\mathrm{pH}$ cycling (Table 2). The percentage of enamel microhardness loss was significantly lower in the group receiving ENA $(p=0.0072)$ (Figure 1). Enamel microhardness presented significantly higher values after treatment of surfaces with ENA and DUR than CLI or the CON group.

There were no significant differences among the groups, regarding enamel microhardness at different depths according to the treatments $(p=0.7536)$, although the microhardness values increased as enamel depth increased ( $p<0.0001)$ (Table 3). Microhardness increased up to a depth of $80 \mu \mathrm{m}$, after which the values remained constant up to $300 \mu \mathrm{m}$, regardless of the treatment.

The polarized light microscopy images show that the subsurface caries lesions were not remineralized with the varnish treatments. The enamel surfaces

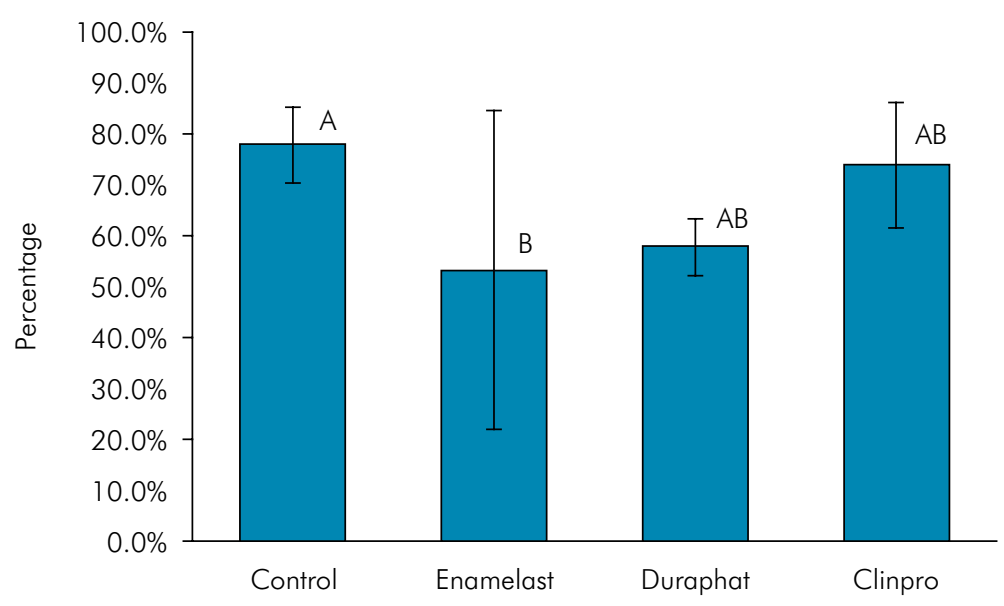

Figure 1. Percentage of microhardness loss according to the treatment used. 
Table 3. Microhardness $\left(\mathrm{kgf} / \mathrm{mm}^{2}\right)$ mean (standard deviation) according to the treatment and the enamel depth.

\begin{tabular}{|c|c|c|c|c|c|}
\hline \multirow{2}{*}{ Depth (um) } & \multicolumn{4}{|c|}{ Treatment } & \multirow{2}{*}{ Tukey } \\
\hline & Control & Enamelast & Duraphat & Clinpro & \\
\hline 10 & 51.82 (36.89) & $67.79(59.24)$ & 49.00 (22.99) & 44.01 (17.67) & $f$ \\
\hline 20 & 84.75 (79.30) & 95.09 (72.57) & $76.06(49.35)$ & $73.26(34.76)$ & $f$ \\
\hline 30 & $104.90(88.05)$ & $128.20(68.93)$ & $127.67(72.02)$ & $125.00(65.09)$ & e \\
\hline 40 & $136.50(54.07)$ & $183.94(59.69)$ & $180.44(73.44)$ & $161.54(90.67)$ & $d$ \\
\hline 50 & $164.29(68.00)$ & $209.80(60.87)$ & 206.14 (53.79) & 195.85 (90.67) & $\mathrm{cd}$ \\
\hline 60 & $193.54(67.80)$ & $225.97(69.40)$ & $210.66(45.99)$ & 226.81 (73.94) & $b c$ \\
\hline 80 & $226.30(66.63)$ & $223.26(65.72)$ & $229.53(47.08)$ & $247.06(41.57)$ & $a b$ \\
\hline 100 & $235.28(69.80)$ & $238.66(71.38)$ & $225.77(54.29)$ & $283.32(51.00)$ & $a$ \\
\hline 120 & $235.03(67.77)$ & $230.38(81.03)$ & $241.09(52.54)$ & $274.06(43.34)$ & $a b$ \\
\hline 140 & 229.45 (61.09) & 235.31 (82.33) & $222.99(65.04)$ & $258.77(50.31)$ & $a b$ \\
\hline 160 & $219.24(56.97)$ & $239.98(51.92)$ & 237.51 (63.97) & $245.78(44.71)$ & $a b$ \\
\hline 180 & $228.39(58.35)$ & $241.84(68.67)$ & $249.75(60.59)$ & 258.40 (51.39) & $a b$ \\
\hline 200 & $234.07(62.41)$ & $247.70(65.96)$ & $260.97(79.03)$ & $260.27(65.73)$ & $a b$ \\
\hline 300 & $238.57(63.08)$ & $242.95(70.29)$ & $160.97(79.03)$ & 259.07 (63.47) & $a b$ \\
\hline Tukey & $A$ & $A$ & $A$ & $A$ & \\
\hline
\end{tabular}

Means followed by different letters (uppercase in rows and lowercase in columns) are different.

treated with the varnishes presented a thinner dark line (indicating demineralization) than the $\mathrm{CON}$ group (that presented a thicker, dark superficial line, indicating a deeper demineralized area than the subsurface area, which was lighter in color) (Figure 2).

Regarding the fluoride concentration of the varnishes, the ENA whole varnish presented higher soluble and insoluble fluoride concentration than the other varnishes evaluated $(\mathrm{p}<0.0001)$. CLI centrifuged varnish presented higher concentration of soluble fluoride than ENA ( $p=0.0015)$ (Table 4).

\section{Discussion}

In the present study, it was found that the varnishes had a limited effect on the remineralization of the enamel surface, since the surface microhardness values after the treatments did not return to their initial values (Table 2). In the protocol used in the present study, the subsurface lesion caries was initially created for subsequent application of the varnish. It simulated a clinical situation in which an initial caries lesion in the enamel would be diagnosed and treated with non-invasive therapies, ${ }^{26}$ and in which the surface and cross-sectional microhardness evaluations would be associated with the dynamics of fluoride use and the remineralization process. ${ }^{26}$ The enamel surface microhardness measurements were not taken after performing the demineralizing cycles to obtain artificial enamel caries lesions, which is a limitation of this study. However, evaluation of the treatments showed that the enamel surface microhardness values were higher with ENA and DUR varnishes than the CON and CLI groups. This suggests that the former agents presented greater potential for enamel surface remineralization than the latter. According to the respective manufacturers, all the varnishes evaluated have a high concentration of $\mathrm{NaF}(22,600 \mathrm{ppm})$ in their composition, resulting in greater remineralization of the most superficial layer of the enamel, and a lesser effect on the deeper layers. ${ }^{26,30-32}$ However, the mean fluoride concentrations found in the varnishes evaluated in this study were lower than the values declared by the manufacturer, especially for CLI, in which a mean of $7336.27 \mathrm{ppm}$ soluble and insoluble fluoride concentration was verified (Table 4), a finding that could explain the results obtained for the surface 

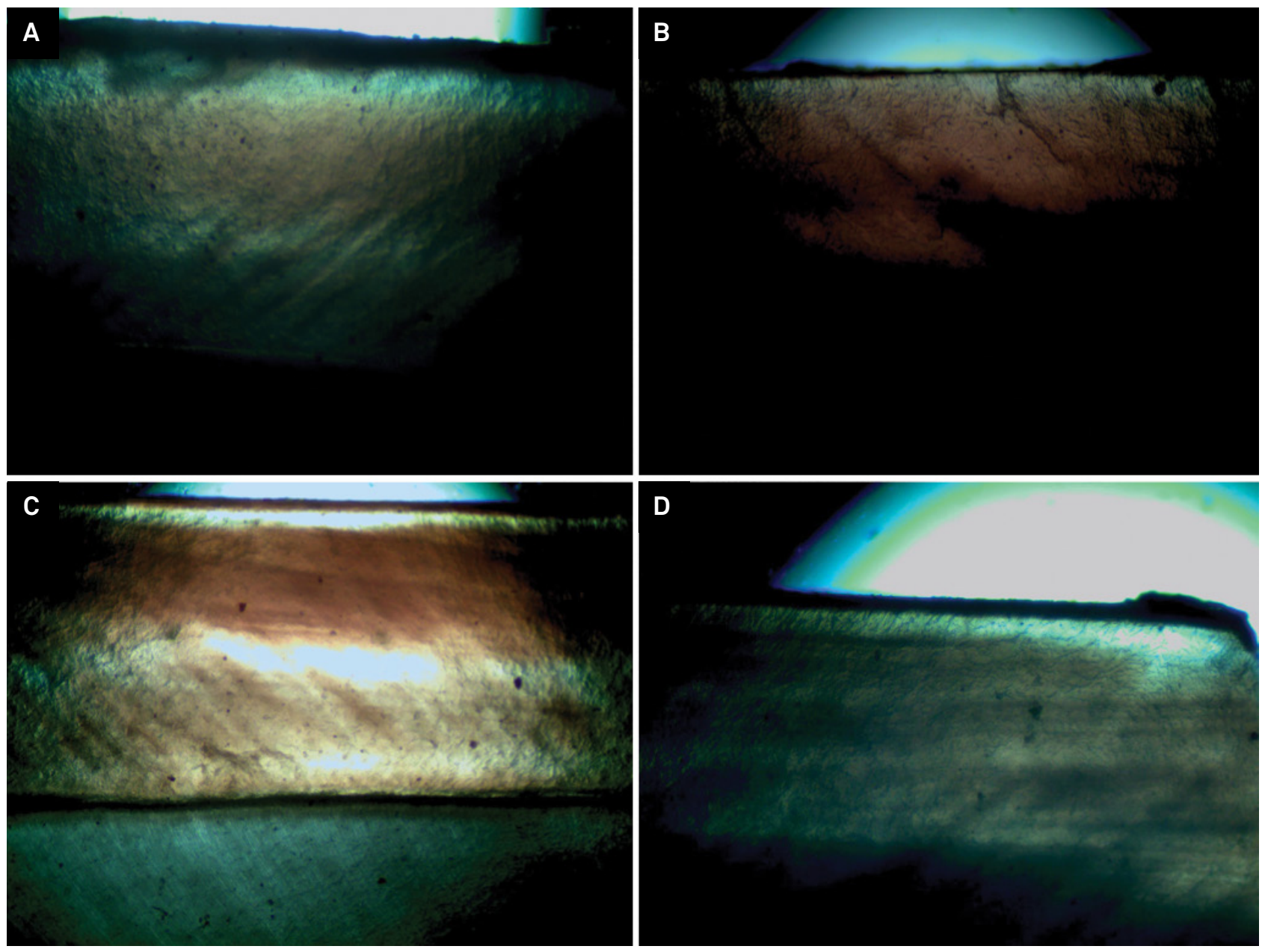

Figure 2. Polarized light microscopy images showing the subsurface caries lesions obtained with $\mathrm{pH}$ cycling, as well as the region of the most mineralized surface, resulting from varnish application. A) Control group, with a dark color in the subsurface area (the most demineralized); B) Enamelast group; C) Duraphat group; D) Clinpro White Varnish group.

Table 4. Fluoride concentration (ppm) median (minimum; maximum) according to the material and the treatment.

\begin{tabular}{lcc}
\hline Varnish & Whole (soluble and insoluble fluoride) & Centrifuged (soluble fluoride) \\
\hline Enamelast & $13932.62(12053.35 ; 17072.19) \mathrm{a}$ & $380.67(217.29 ; 2726.93) \mathrm{b}$ \\
Duraphat & $11555.69(6621.69 ; 12734.90) \mathrm{b}$ & $908.59(626.56 ; 4369.28) \mathrm{ab}$ \\
Clinpro White Varnish & $7336.27(3817.71 ; 11661.97) \mathrm{b}$ & $2966.63(513.37 ; 7023.97) \mathrm{a}$ \\
\hline
\end{tabular}

Medians followed by different letters in columns are different $(p \leq 0.05)$.

enamel. The protocol to solubilize the resin in the varnishes to enable fluoride evaluation is a repetitive process that demands successive acetone washes. Furthermore, it is believed that there is a weak release of the fluoride content due to the hydrophobic resin content. ${ }^{11}$ Although repetitive acetone washes and centrifugation of the varnishes were performed, it may not have been possible to achieve completely solubilized varnish; this would explain the differences in the fluoride concentration values between those obtained in our study and those appearing on the label.

The reaction of the varnish with the enamel, in the short term, is dependent on its soluble fluoride 
concentration, and, in the long term, on dissolution of the insoluble fluoride present in the varnish matrix. ${ }^{26}$ In the present study, the varnishes were applied on enamel subsurface caries lesions, after which dynamic $\mathrm{pH}$ cycling for induction of remineralization was carried out for 6 days. The reaction of the fluoride in varnishes with enamel is time-dependent. The insoluble fluoride in the formulation plays a significant role in slowing this process, in comparison with the soluble fluoride concentration, which is responsible for chemically forming fluoride calciumlike reservoirs on the enamel, over a short period of time (after a professional fluoride application, for example). ${ }^{26}$

Although a lower concentration of insoluble and soluble fluoride was observed for CLI, the presence of modified tri-calcium phosphate could potentiate enamel remineralization, ${ }^{33,34}$ especially at greater depths, ${ }^{35}$ since remineralization of the enamel surface does not promote remineralization of the subsurface caries lesion. ${ }^{36}$

Modified tri-calcium phosphate (or functional tri-calcium phosphate) crystalline form provides a calcium and phosphate release system obtained by milling beta-calcium phosphate with sodium lauryl sulfate. ${ }^{34}$ In the varnish containing modified tri-calcium phosphate, used in the present study, there is another component (fumaric acid) in the formulation that prevents undesirable chemical bonding between the calcium and the phosphate. ${ }^{19,35}$ In other studies, CLI was found to present results similar to DUR regarding surface microhardness, ${ }^{19}$ and even higher values than the other varnishes studied. ${ }^{33,37,38}$ However, the effect of potentiating enamel remineralization promoted by this varnish was not observed in the present study, even when analyzing the microhardness at different depths (Table 3).

The percentage of surface microhardness loss enables an indirect evaluation of the amount of mineral loss from the enamel following the varnish application treatments (Figure 1). In this regard, ENA varnish had less surface microhardness loss in relation to the CON group. The concentration of soluble and insoluble fluoride present in the varnish, and the possible release of fluoride by the varnish-which may interfere in $\mathrm{CaF}_{2}$ deposition on the surface- was higher for ENA than for the other varnishes (Table 5). Furthermore, it is suggested that, although all varnishes remained on the enamel surface for the same amount of time, the fluoride released by ENA might have been higher than that released by the other varnishes, although this property was not evaluated in the present study. Carvalho et al. ${ }^{23}$ observed that the greater contact time promoted by ENA varnish may have influenced the amount of fluoride deposited on the enamel, thus suggesting that the lower viscosity of certain varnishes may promote stronger retention on enamel, provide greater contact with the storage medium, and allow greater release of fluoride. In addition, Al Dehailan et al. ${ }^{21}$ observed that different varnish compositions may interfere with the remineralization of enamel lesions, the release of fluoride and the deposition of fluoride on the dental surface. Therefore, the concentration of the soluble and insoluble fluoride should explain this result, since ENA presented higher fluoride concentration than the other varnishes.

The effect of treatments using varnish for remineralization of subsurface caries lesion was evaluated by the cross-sectional in-depth microhardness analysis. It was verified that no varnish was able to provide remineralization of subsurface lesions, further corroborated by the polarized light microscopy images. The amount of soluble and insoluble fluoride concentration did not attain the levels stated by the manufacturers. Although this study used a standardized protocol to evaluate the soluble and insoluble fluoride concentrations, the varnish may not have been completely solubilized due to the hydrophobic synthetic resin content. This would explain the differences in the fluoride concentration values between those obtained in our study and those appearing on the label, despite successive acetone washes to provide varnish solubilization. However, it could also be that the fluoride content in the varnish is not the same as that stated by the manufacturers. This study presented some limitations, such as not measuring the microhardness values after demineralization cycles and not reporting the amount of fluoride released by the varnishes during the remineralizing cycles. Nevertheless, it should be considered that the remineralization process 
occurs more slowly in the deeper layers than on the surface, and is greatly improved by products containing tri-calcium phosphate. ${ }^{35}$ In this respect, the surface layer of the enamel is better benefited by the presence of the fluoride available in and released by the varnishes. ${ }^{31}$

\section{Conclusions}

Enamelast and Duraphat varnishes had a remineralizing effect on the enamel surface, but no varnish was able to remineralize the lesion subsuperficially. Although insoluble and soluble fluoride concentration levels did not correspond to those declared by the manufacturer, Enamelast had a higher fluoride concentration than the other varnishes.

\section{Acknowledgments}

The authors would like to thank CNPq (process number 113838/2016-6) for providing the grants, Ultradent Products, for providing the Enamelast varnish for the tests, and FAPESP (process number 2016/13786-0) for providing the equipment for fluoride concentration analysis.

\section{References}

1. Cury JA, Tenuta LM. Enamel remineralization: controlling the caries disease or treating early caries lesions? Braz Oral Res. $2009 ; 23$ Suppl 1:23-30. https://doi.org/10.1590/S1806-83242009000500005

2. Gibson G, Jurasic MM, Wehler CJ, Jones JA. Supplemental fluoride use for moderate and high caries risk adults: a systematic review. J Public Health Dent. 2011;71(3):171-84. https://doi.org/10.1111/i.1752-7325.2011.00261.x

3. Tellez M, Gomez J, Kaur S, Pretty IA, Ellwood R, Ismail Al. Non-surgical management methods of noncavitated carious lesions. Community Dent Oral Epidemiol. 2013 Feb;41(1):79-96. https://doi.org/10.1111/cdoe.12028

4. Marinho VC, Higgins JP, Logan S, Sheiham A. Fluoride varnishes for preventing dental caries in children and adolescents. Cochrane Database Syst Rev. 2002;(3):CD002279. https://doi.org/10.1002/14651858.CD002279

5. Queiroz CS, Hara AT, Paes Leme AF, Cury JA. pH-cycling models to evaluate the effect of low fluoride dentifrice on enamel de- and remineralization. Braz Dent J. 2008;19(1):21-7. https://doi.org/10.1590/S0103-64402008000100004

6. Lenzi TL, Montagner AF, Soares FZ, de Oliveira Rocha R. Are topical fluorides effective for treating incipient carious lesions?: A systematic review and meta-analysis. J Am Dent Assoc. 2016 Feb;147(2):84-91.e1. https://doi.org/10.1016/i.adaj.2015.06.018

7. Gao SS, Zhang S, Mei ML, Lo EC, Chu CH. Caries remineralisation and arresting effect in children by professionally applied fluoride treatment - a systematic review. BMC Oral Health. 2016 Feb;16(1):12. https://doi.org/10.1186/s12903-016-0171-6

8. Marinho VC, Worthington HV, Walsh T, Clarkson JE. Fluoride varnishes for preventing dental caries in children and adolescents. Cochrane Database Syst Rev. 2013 Jul;7(7):CD002279. https://doi.org/10.1002/14651858.CD002279.pub2

9. ten Cate JM. Current concepts on the theories of the mechanism of action of fluoride. Acta Odontol Scand. 1999 Dec;57(6):325-9. https://doi.org/10.1080/000163599428562

10. Tenuta LM, Cerezetti RV, Del Bel Cury AA, Tabchoury CP, Cury JA. Fluoride release from CaF2 and enamel demineralization. J Dent Res. 2008 Nov;87(11):1032-6. https://doi.org/10.1177/154405910808701105

11. Fernández CE, Tenuta LM, Zárate $P$, Cury JA. Insoluble NaF in Duraphat $\AA$ may prolong fluoride reactivity of varnish retained on dental surfaces. Braz Dent J. 2014;25(2):160-4. https://doi.org/10.1590/0103-6440201302405

12. Bruun C, Givskov H. Formation of CaF2 on sound enamel and in caries-like enamel lesions after different forms of fluoride applications in vitro. Caries Res. 1991;25(2):96-100. https://doi.org/10.1159/000261350

13. Retief DH, Sorvas PG, Bradley EL, Taylor RE, Walker AR. In vitro fluoride uptake, distribution and retention by human enamel after 1- and 24-hour application of various topical fluoride agents. J Dent Res. 1980 Mar;59(3):573-82. https://doi.org/10.1177/00220345800590030401

14. Du M, Cheng N, Tai B, Jiang H, Li J, Bian Z. Randomized controlled trial on fluoride varnish application for treatment of white spot lesion after fixed orthodontic treatment. Clin Oral Investig. 2012 Apr;16(2):463-8. https://doi.org/10.1007/s00784-011-0520-4

15. Arruda AO, Senthamarai Kannan R, Inglehart MR, Rezende CT, Sohn W. Effect of $5 \%$ fluoride varnish application on caries among school children in rural Brazil: a randomized controlled trial. Community Dent Oral Epidemiol. 2012 Jun;40(3):267-76. https://doi.org/10.1111/j.1600-0528.2011.00656.x

16. Giacaman R, Fernández C, Muñoz-Sandoval C, Fuentes N. Longer retention time of fluoridated varnishes enhances enamel remineralisation in vitro. Oral Health Prev Dent. 2017;15(6):569-73. https://doi.org/10.3290/i.ohpd.a38778 
Remineralizing effect of commercial fluoride varnishes on artificial enamel lesions

17. Sköld-Larsson K, Modéer T, Twetman S. Fluoride concentration in plaque in adolescents after topical application of different fluoride varnishes. Clin Oral Investig. 2000 Mar;4(1):31-4. https://doi.org/10.1007/s007840050110

18. Weintraub JA, Ramos-Gomez F, Jue B, Shain S, Hoover Cl, Featherstone JD, et al. Fluoride varnish efficacy in preventing early childhood caries. J Dent Res. 2006 Feb;85(2):172-6. https://doi.org/10.1177/154405910608500211

19. Mohd Said SN, Ekambaram M, Yiu CK. Effect of different fluoride varnishes on remineralization of artificial enamel carious lesions. Int J Paediatr Dent. 2017 May;27(3):163-73. https://doi.org/10.1111/ipd.12243

20. Silverstone LM. Remineralization of human enamel in vitro. Proc R Soc Med. 1972 Oct;65(10):906-8.

21. Al Dehailan L, Martinez-Mier EA, Lippert F. The effect of fluoride varnishes on caries lesions: an in vitro investigation. Clin Oral Investig. 2016 Sep;20(7):1655-62. https://doi.org/10.1007/s00784-015-1648-4

22. Bolis C, Härtli GP, Lendenmann U. Hertli GP, Lendenmann U. Fluoride varnishes: is there a correlation between fluoride release and deposition on enamel? Oral Health Prev Dent. 2015;13(6):545-56. https://doi.org/10.3290/i.ohpd.a34373

23. Carvalho TS, Peters BG, Rios D, Magalhães AC, Sampaio FC, Buzalaf MA, et al.; Braz. oral res. Correction: Fluoride varnishes with calcium glycerophosphate: fluoride release and effect on in vitro enamel demineralization. Braz Oral Res. 2015;29(1):1-6. https://doi.org/10.1590/1807-3107BOR-2015.vol29.0092

24. Punathil S, Pulayath CV, Ismail SP, Bavabeedu SS, Moyin S, Uthappa R. Assessment of enamel surface microhardness with different fluoride varnishes-an in vitro study. J Contemp Dent Pract. 2018 Nov;19(11):1317-21. https://doi.org/10.5005/ip-journals-10024-2425

25. Oliveira MR, Oliveira PH, Oliveira LH, Horliana AC, César PF, Moura SK, et al. Microhardness of bovine enamel after different fluoride application protocols. Dent Mater J. 2019 Feb;38(1):61-7. https://doi.org/10.4012/dmj.2017-399

26. Manarelli MM, Delbem AC, Lima TM, Castilho FC, Pessan JP. In vitro remineralizing effect of fluoride varnishes containing sodium trimetaphosphate. Caries Res. 2014;48(4):299-305. https://doi.org/10.1159/000356308

27. Spiguel MH, Tovo MF, Kramer PF, Franco KS, Alves KM, Delbem AC. Evaluation of laser fluorescence in the monitoring of the initial stage of the de-/remineralization process: an in vitro and in situ study. Caries Res. 2009;43(4):302-7. https://doi.org/10.1159/000218094

28. Vieira AE, Delbem AC, Sassaki KT, Rodrigues E, Cury JA, Cunha RF. Fluoride dose response in pH-cycling models using bovine enamel. Caries Res. 2005 Nov-Dec;39(6):514-20. https://doi.org/10.1159/000088189

29. Silverstone LM. The surface zone in caries and in caries-like lesions produced in vitro. Br Dent J. 1968 Aug;125(4):145-57.

30. Altenburger MJ, Schirrmeister JF, Wrbas KT, Klasser M, Hellwig E. Fluoride uptake and remineralisation of enamel lesions after weekly application of differently concentrated fluoride gels. Caries Res. 2008;42(4):312-8. https://doi.org/10.1159/000148164

31. Buzalaf MA, Pessan JP, Honório HM, ten Cate JM. Mechanisms of action of fluoride for caries control. Monogr Oral Sci. 2011;22:97-114. https://doi.org/10.1159/000325151.

32. Lagerweij MD, Buchalla W, Kohnke S, Becker K, Lennon AM, Attin T. Prevention of erosion and abrasion by a high fluoride concentration gel applied at high frequencies. Caries Res. 2006;40(2):148-53. https://doi.org/10.1159/000091062

33. Elkassas D, Arafa A. Remineralizing efficacy of different calcium-phosphate and fluoride based delivery vehicles on artificial caries like enamel lesions. J Dent. 2014 Apr;42(4):466-74. https://doi.org/10.1016/i.jdent.2013.12.017

34. Karlinsey RL, Mackey AC, Walker ER, Frederick KE. Surfactant-modified beta-TCP: structure, properties, and in vitro remineralization of subsurface enamel lesions. J Mater Sci Mater Med. 2010 Jul;21(7):2009-20. https://doi.org/10.1007/s10856-010-4064-y

35. Balakrishnan A, Jonathan R, Benin P, Kuumar A. Evaluation to determine the caries remineralization potential of three dentifrices: an in vitro study. J Conserv Dent. 2013 Jul;16(4):375-9. https://doi.org/10.4103/0972-0707.114347

36. Cochrane NJ, Cai F, Huq NL, Burrow MF, Reynolds EC. New approaches to enhanced remineralization of tooth enamel. J Dent Res. 2010 Nov;89(11):1187-97. https://doi.org/10.1177/0022034510376046

37. Alamoudi SA, Pani SC, Alomari M. The effect of the addition of tricalcium phosphate to $5 \%$ sodium fluoride varnishes on the microhardness of enamel of primary teeth. Int J Dent. 2013;2013:486358. https://doi.org/10.1155/2013/486358

38. Tuloglu N, Bayrak S, Tunc ES, Ozer F. Effect of fluoride varnish with added casein phosphopeptide-amorphous calcium phosphate on the acid resistance of the primary enamel. BMC Oral Health. 2016 Sep;16(1):103. https://doi.org/10.1186/s12903-016-0299-4 